\title{
Re-examining narrativity: Small stories in status updates
}

\author{
RUTH PAGE
}

\section{Abstract}

Social networking sites are an increasingly prominent form of computermediated communication that provides a venue for individuals to document their life experience through the publication of "status updates." The stories reported in updates fall outside the literary, conversational, and electronic narrative canon, but are a rich data source for re-examining key concepts in narrative theory, including factors that give rise to perceptions of narrativity. This article examines the narrative potential of status updates found in the social network site Facebook, based on the analysis of just under 2000 updates posted by British users. The episodic narrativity of the updates is influenced by the online discourse situation where recency is prized over retrospection and updates are distributed within a multidimensional web of connections between Facebook Friends. The narrativity represented in the surface features and genres of the status stories are characterized by the present tense of Breaking News (Georgakopoulou 2007) and archived in reverse chronological order. These narrative characteristics are in keeping with stories in other Web genres (blogs, e-mail, discussion forums) and suggest that the parameters associated with prototypical narrativity are by no means abstract or universal, but constrained by the canonical data from which they were originally derived.

Keywords: narrative; status updates; social networking sites; Facebook; small stories; temporality.

\section{Introduction}

Contemporary narrative analysis has moved a long way from the universalizing assumptions of structuralist narratology which sought to establish abstract models able to account for the workings of all narrative. Despite recognizing the heterogeneity of the narrative corpus, the tendency to privilege certain

1860-7330/10/0030-0423

Online 1860-7349

(C) Walter de Gruyter
Text \& Talk 30-4 (2010), pp. 423-444 DOI 10.1515/TEXT.2010.021 


\section{Ruth Page}

story forms over others has left a legacy for postclassical narrative theory in the form of a perceived narrative canon. The formation of this canon can be traced to the focus on literary texts in classical narratology and to the influence of Labov's (1972) work on personal narratives in sociolinguistics. Although clearly not representative of all narrative analysis, the prioritizing of singleteller, past event stories has contributed to the categories and qualities associated with prototypical narratives and from which discussions of narrativehood and narrativity (Herman 1997) have been derived. In response, there have been calls to pay closer attention to stories that fall outside the dominant traditions of narrative analysis (Ochs and Capps 2001; Georgakopoulou 2007), particularly investing value in the fragmentary and ephemeral stories told in everyday contexts.

At the same time that the narrative canon was being challenged, the evolution of narratives told using digital media provided a range of alternative storylike forms which enabled theorists to rework key concepts in narrative theory, including debates about what constituted narrative itself (Ryan 2006). The development of digital narratology was prompted initially by the emergence of electronic literature and the fictional worlds created in video gaming or role playing simulations. More recently, access to and patterns of Internet usage have widened the range of narratives available in digital media, and at the beginning of the twenty-first century, the artistic endeavors of electronic literature are complemented by stories of personal experience that proliferate in blogs, discussion forums, and social networking sites. The discussion of narratives presented here proceeds from two points of impetus. First, it extends the analysis of stories that fall outside the canon of personal narrative to include those that are created in online environments. Second, it calls for a paradigm shift in digital narratology toward a contextually sensitive account that captures more adequately the ways in which online storytelling can emerge as situated practice. The stories under scrutiny here are those published as "status updates" in a relatively recent form of computer-mediated communication: social network sites (SNS). I examine the narrative-enabling and -constraining features of one particularly prominent social network site (Facebook), outlining the factors which enable status updates to be interpreted as a specific subgenre of storytelling.

\section{Social networking sites: definitions and history}

Social networking sites (SNS) began to emerge in the last decade of the twentieth century and have since expanded both in range and in usage. Subject to sensationalist treatment in the media, sites which use social software to promote connection between their users (well-known current examples include Facebook, MySpace, YouTube, and Flickr) are now recognized as the mainstay 
of Internet usage on an international scale. SNS typically combine features which Boyd and Ellison (2007) define as offering users a public or semi-public profile within a bounded system; an articulated list of other users with whom the user shares an interest, and the ability to traverse the list of connections made by themselves and others within the system.

Facebook was first launched as a network for a niche community in 2004, when it was made available to Harvard college students only. In the five years following, it achieved remarkable uptake outside that original community and is currently the most frequently used SNS in the United Kingdom, boasting 17 million unique visitors each month (Kazeniac 2009). Facebook is clearly embedded in a participatory culture (Jenkins 2006), where the more static display of personal profile information is framed by a variety of communicative channels for interaction. Friends can send each other e-mail messages, use an instant messenger service, join discussion threads, share photographs and tag one another in them, post public messages on another user's profile (in Facebook terminology, their "wall"), and send messages about their current activity via a "status update" to all the Friends on their list. Facebook's community is best described as a "networked public" (Boyd 2008: 25): a public transformed by the practices and potential of networked media. In particular, the networks in Facebook are characterized by collapsed contexts where groups usually segmented in offline contexts are brought together in one environment. Interaction with Friends on Facebook (such as posting an update) might be understood as one measure which offsets the necessarily discontinuous nature of the social relationships between the writer and their Friends (Sigman 1991), acting as a means by which the participants can make social realities like relationships "real" (Leeds-Hurwitz 2005).

Status updates appear in the individual's profile in a standardized template where the user is prompted to respond to the question "What are you doing right now?" by completing the phrase " $\mathrm{X}$ is ...". ${ }^{1}$ The status update then appears in the individual's profile and is distributed into the news feeds of all Friends listed on the individual's group. Over time, the updates compose an archive which documents an ongoing narrative of the writer's life experiences. At the time when the data for this project was collected, updates appeared the least dialogic of interaction forms on Facebook, for they did not contain a commenting facility. ${ }^{2}$ Instead, the audience could respond to an update by privately emailing the writer, or posting a semi-public message on their wall. For example, when a writer announced they were expecting a baby via their status update, their wall was quickly filled with congratulatory messages. Similarly, an update indicating that a writer had received bad news prompted messages of condolence or concern. The variation in response channels makes it difficult to track correlations between status update and specific patterns of feedback within this sample. Thus while the updates must be understood as shaped by 
their rhetorical context, the following analysis focuses on the status updates themselves. ${ }^{3}$

The sample of status updates was taken from the profiles of 100 white British Facebook users. ${ }^{4}$ The status updates were tracked for a two-month period, yielding a total of 1906 updates. As single teller accounts of life experience oriented to the teller's social self, status updates share some affinity with the genre of life history (Linde 1993). Like life histories, the developing archive of status updates is a necessarily discontinuous and open unit that unfolds over time and is revised in keeping with the writer's life experiences. But the reports posted in status updates are neither extensive in length, nor do they focus on significant episodes in the speaker's history. Instead, status updates typically focus on the minutiae of everyday events. Writers update about a range of topics, including the weather, their mood, travel, leisure activities, preparing food, or domestic chores. The content of the updates contrasts with the dramatic disruptions found in canonical narrative studies (cf. Labov's "danger of death corpus"). Instead, the updates may be aligned with Malinowski's concept of phatic communion, where utterances with unexceptional content are used to signal communicative connection between the writer and their Friends (Jakobson 1988 [1960]). In order to account for these highly non-canonical stories, we need to move beyond prototypical models of narrative structure which emphasize past tense stories with a tellability which emphasizes "conflict" (Herman 2007: 10). Instead, updates are highly suggestive of the genre described by Georgakopoulou (2007) as small stories. Small stories are characterized by fluidity, plasticity, and open-endedness, usually occurring in the small moments of talk, rather than as distinct, fully fledged units (Georgakopoulou 2007: 36). As Georgakopoulou's work readily attests, extending narrative analysis to take account of these everyday, interactional stories is a useful means by which key concepts of narrative structure and function can be revisited and reworked. In the same spirit, I approach the analysis of status updates in order to understand more fully the narrative potential of this form of online communication.

\section{The issue of narrative definition}

Determining the narrative potential of the status updates requires the analyst to confront the well-documented dilemma of trying to define narrative in the first place. This is no simple task. While minimal definitions based on obligatory criteria enabled clear-cut contrasts between whether a text was deemed to be a narrative or not, the verbally oriented nature of definitions was found to be too restrictive and unable to account for the expansive diversity of texts that readers recognized as story-like. On the other hand, opening up the category of 
2

narrative so far that seemingly anything might count as a story (such as a list of Facebook wall posts) both idealizes narrative as a form and dilutes its clarity so far as to render it almost unusable (Ryan 2006). In seeking an intermediate position between the polarities of minimal narrative criteria and generic openness, attempts to pin down narrative and its characteristics have burgeoned. Binary models of definition have been rejected in favor of perceiving narrative as a fuzzy set where qualities of narrativity enable texts to be more or less easily recognized as narrative-like. These qualities of narrativity are not tied to specific linguistic forms (e.g., past-tense finite verbs). Instead, narrative is understood as a cognitive construct, built in response to stimuli that can be found in various media (Ryan 2004: 8) and shaped by the reader/hearer's pre-existing world knowledge (Herman 1997). The exact characteristics said to contribute to the perception of narrativity are many and various, but notably have been influenced by the dataset typical of the narrative canon. A full survey falls beyond the remit of this paper, and I refer the interested reader to Ryan (2004, 2006, 2007) for a more extensive review.

Three semantic properties are significant for the analysis of narrativity in Facebook's status updates. First, narrativity is generated by the recognition of reported events, ordered within a temporal framework, and experienced by an individuated existent who acts as a filtering consciousness which makes sense of them. More contentiously, the inferred connections between temporally ordered events are attributed with distinctive degrees of narrativity. Typically, causal connections are understood as more narrative-like than pure temporality, especially when combined into macro-level sequences which constitute a unified whole (Giora and Shen 1994). Strong narrativity is associated with sequences which signal a teleological focus, an over-arching framework of complication and resolution, and/or a clearly defined point of closure which is often laden with interpretive significance.

The perception of temporality, a framing consciousness, and a holistic sequence are by no means the only qualities that contribute to the identification of narrative. Nor does the reiteration of these qualities resolve the hegemonic status of the canonical texts that underpin notions of prototypical narrativity. Rather, these narrative characteristics are regarded as a starting point which in turn might be stretched and enriched by the examination of data that is a far cry from the lengthy complexity of literary narratives or self-contained narratives of personal experience.

\section{Narrative characteristics of the status update}

As a self-contained unit, the status update can be interpreted as bearing certain narrative properties. First, the update always contains reference to an 
individual who reports their experiences: the writer themselves. The articulation of a named individual is automatically generated in the update template by the Facebook interface as the start point from which any and all updates are completed. The stated name is crucial information for both narrative production (self-representation) and reception (for the audience to know who the update is about). Facebook's template also generates a timestamp, which appears at the header and footer of each update and fixes the report of events chronologically with a date and time. As the time of narration is understood to be near simultaneous with the time of reported events, this enables the audience to reconstruct a chronological position for the updated events. Within updates, writers may also report multiple events which are structured around a temporal sequence, as the following examples indicate.

(1) June 20

Nancy wishes Jacob had never started the 'let's chalk on the patio' game ... every inch of it is covered now and he's started up the fences and house...

10:20am

(2) February 16

Sandra has had a lovely week end with the bestest of friends and great church in nicetown. goin to bed now as robert needs lift at 4.00 tomoz ugh!!!

$11.51 \mathrm{pm}$

(3) June 9

Veronica declared war on vegetation in the front garden yesterday and is hoping to go back to the front line for a while this evening without being eaten alive by bugs!

$6: 43 \mathrm{pm}$

Even a cursory glance at these examples shows that the temporality constructed in the status updates is quite distinct from the past-tense forms typically used to narrate more canonical personal experience narratives or life histories. Against the backdrop of a-personal cosmic time, the writer's status updates can be seen in Ricoeur's (1984: 52) terms as an attempt to "make time human" by selecting particular events as worthy of narration while other material is not. However, the human time depicted in the updates themselves is not constructed as a linear string of dates that positions the events in the distant past. Rather, as Ochs and Capps (2001: 157) put it, human time is "sensed holistically" where the past and future are brought to bear on the present moment.

The use of the present tense in storytelling is not unusual, and has been documented as a means of segmenting narrative (Wolfson 1978) and coincid- 
ing with evaluative high points (Schiffrin 1981) when used as an alternative to conventions of past-tense reporting. However, we might interpret the significance of the "pull of the present" found in these status stories in terms of the particular context created by the social network. Superficially, the preeminence of the present moment in status updates may be in part a result of the immediate discourse situation. After all, the prompt for the status update asks the writer what they are doing "right now," not what they were doing at some point earlier in their life. Given that the English present tense is described as "timeless" (Wolfson 1978: 222) and able to incorporate reference to a range of times (Schiffrin 1981: 46), the ambiguity can be deployed here in order to bridge the temporal gap between the times of narrative production and reception caused by the asynchronous nature of computer-mediated communication.

The importance of the present moment is reflected in the categories of stories that are told in the status updates. Since Labov's work on personal narrative, others have recognized that stories are not always narrated in the past tense (Ochs and Capps 2001; Norrick 2000). Georgakopoulou's (2007) work on small stories provides useful additional distinctions that can be used to classify story types, especially those that report events characterized like the updates by "some kind of immediacy" (2007: 40). Georgakopoulou identifies a range of small stories, which include "Breaking news stories" where "tellers seem to wish to share the reported events straight away, as they are still unfolding" (2007: 42) and "Projections" where the speaker constructs a taleworld of events which have not yet happened (2007: 47). The key distinction between these story genres appears to rest on the direction of the temporal span interpreted between the assumed time of the reported events and the time of narration. Past event stories emphasize retrospection, where the reported events are deemed to have taken place prior to the point of narration. Breaking news stories represent reported events as taking place near-simultaneously with the act of narration. Projections are anticipatory in character and report events which will happen later than the point of narration. There are at least three sets of cues that the reader may use when interpreting the temporal span between the narration and the reported events (and hence the small story genre): the time of narration indicated by Facebook's timestamp; references to time within an update (e.g., later, tomorrow); and the use of verb tenses.

As Georgakopoulou notes, unlike the predominance of past event stories in conventional narrative analysis, Projections and Breaking News stories occur frequently in conversational data, but have been marginalized in narrative analysis on account of their non-canonical features. Similarly, the stories told in status updates reverse the trend of canonical narrative, for reports of nonrecent events are relatively rare while Breaking News and Projections are more common. All 1906 status updates were classified according to the type of small story they contained. The results are summarized in Table 1. 
Table 1. Distribution of small stories in the status update sample

\begin{tabular}{llll}
\hline Projections & Past tense & Breaking News & Total \\
\hline $21.16 \%$ & $15.76 \%$ & $63.09 \%$ & $100.00 \%$ \\
\hline
\end{tabular}

\subsection{Past events}

Although status updates can report past events, this was the least frequently occurring type of small story ( $15 \%$ of the sample). Unlike life stories or danger of death accounts, the time span referred to in the updates usually extends only into the recent past. Of the sample considered here, references to past moments of time only go as far back as a week prior to the point of posting:

(4) July 25

Maureen wishes it was this time last week ... I was poolside :-(.

$2: 18 \mathrm{pm}$

But more often, status updates report events so that they appear to have occurred immediately before the time of narration. Frequently, the past tense verb is preceded by the modifier just, as in the following examples:

(5) May 14

Lily has just had a lovely chinese! Yummy!

7:50pm

(6) April 15

Karen just shut her finger in the car door :(.

$7: 13 \mathrm{pm}$

(7) May 19

Thomas has just made the best sandwich ever.

$2: 56 \mathrm{pm}$

The past time of status updates is not one of distant retrospection, but of events in close proximity to the present moment of narration.

\subsection{Projections}

Writers may also update their status with projections of events to take place in the future, accounting for approximately $21 \%$ of the updates in this sample. As with the past events, Projections usually refer to the time span near to, if not immediately following, the time of the update. In the examples that follow, when writers refer to precise points in the future, these are localized, such as tomorrow and then, or allude to close temporal proximity to the time of reporting with the phrase about to. 
(8) July 5

Sienna is off to the school summer fayre then the cricket club for a nice wee drinkie!

2:42pm

(9) July 6

Gerry is about to eat scrambled eggs.

$11: 35 \mathrm{pm}$

(10) July 18

Samantha is sad that it's Keira's last day tomorrow! What will we EVER do without her?

\section{1:57am}

The events told in Projections are in the irrealis mode, so may not be considered as high in narrativity as retrospective reports of actions which are assumed to have actually occurred. Nonetheless, even while operating in the realm of as yet unrealized actions, these status updates are still emplotments, albeit of the most minimal kind. Sienna's update contains temporally ordered plans, while Samantha invites shared speculation as to the outcome of a shared loss.

\subsection{Breaking News}

By far the most frequently occurring small story genre was Breaking News, accounting for $63 \%$ of the status updates in the sample. The kinds of stories reported as Breaking News are highly heterogeneous. Within this dataset, three sub-types were identified: those which concern Events, External States, or Internal States. Each has different qualities of narrativity.

4.3.1. Breaking News: events. Examples of Breaking News stories which report events include the following:

(11) April 12

Michael is medium term planning!

$6: 22 \mathrm{pm}$

(12) June 25

Robert Pushing back from the gate at LHR.

$4: 55 \mathrm{pm}$

(13) June 24

Simon is giving flowers to all the poorly ladies he knows.

11:23am 


\section{Ruth Page}

Breaking Stories are characterized by the use of the present tense, especially when combined with the progressive aspect. This may result in part from the default setting in the status update prompt, which begins " $\mathrm{X}$ is. ..." This formulation anticipates that the writer will most likely post an update in the present tense (the writer will have to make a conscious effort to delete the verb particle $i s$ if they wish to write something other). Nonetheless, it is worth exploring the narrative effects of the present tense in this context. The present-tense narration creates the illusion that the reported event is happening at the same time the update is being written. Of course, there is usually a delay caused by the operation of actually writing the update: it is not that the narrative tempo exactly coincides with the time of narration. However, this convention is generally understood, and the illusion of the update being anchored in a present moment is shared by both writer and audience.

Both the simple present and the present progressive are low in telicity, such that the boundedness of the reported event is not clear (Hopper and Thompson 1980). The reader cannot be sure exactly when the reported event started or will finish. Together, these semantic qualities explain why the present tense is not the default for reporting (written) narratives. Instead, Schiffrin (1981) points out that the progressive aspect typically occurs in the Orientation and Evaluation sections, where the function of providing either ongoing situational information or an effect of immediacy is critical. In status updates, both the effects of continuity and immediacy are apt as a means of constructing a discourse of a shared present moment. Although the writer and their audience may not be online at the same time and the audience can only experience the update retrospectively, the temporality typical of the Breaking News stories allows readers to participate in the illusion that they are co-spectating on the writer's life experiences as the events themselves are happening. The human time of the status updates is thus inherently social in its potential to forge connections between storytelling participants.

4.3.2. Breaking News: external and internal states. There are many Breaking News updates that do not appear very event-like at all, and we may go as far as to question whether these updates count in their own right as narrative. Many updates report states that describe the writer (rather than their actions) in some way. These descriptions can detail the location of the writer (an external state), their feelings or personal attributes (internal states). Examples of each are given below:

(14) May 29

Frances is in starbucks.

$5: 25 \mathrm{pm}$ 


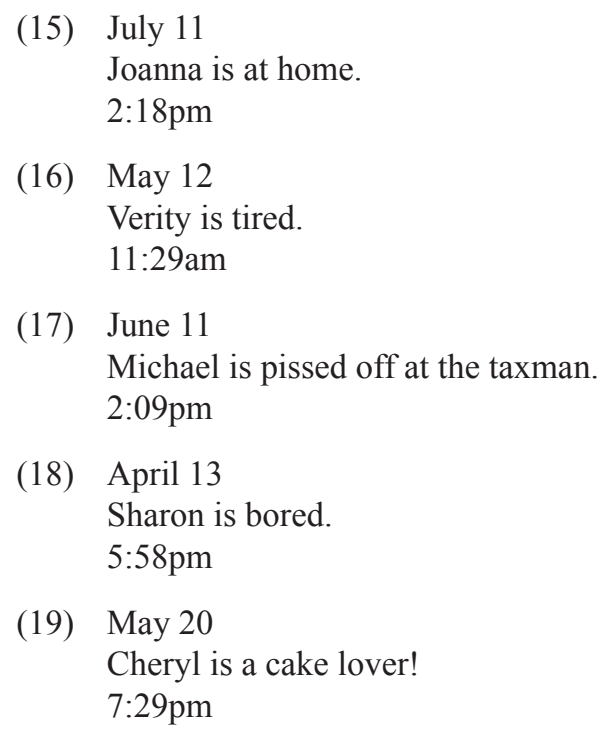

According to Labov's model, these status updates provide Orientation material about the narrative participants and their location. From a textual perspective, clauses containing Orientation material were not considered to be part of the narrative skeleton (Labov 1972: 361), providing a static background to narrative action (Georgakopoulou 2007: 79). However when storytelling is understood as a situated practice, Orientation material might be reconsidered as contributing to the plotline. The rhetorical situation created by updating in Facebook is a case in point. Status updates are posted and distributed within time, but unlike fictional serials, the material reported in the update is assumed to match (approximately) the time and events of the update-writer's lived experiences. Information about the writer's mood or location is not interpreted as a once and for all state that will hold true in the context of future events recorded in later updates. Instead, updates that document the writer's position or stance within their lifeworld are assumed to hold true at the time of narration (indicated by the timestamp) but not necessarily for any longer. Indeed, where an internal or external state is sustained until the next update, the writer usually marks this as unusual, as the following two pairs attest.

(20) June 25

Josh is tired!! Must be the lack of proper coffee.

$10.34 \mathrm{am}$

Josh is still tired!! Even with the expensive coffee!!!

$11.03 \mathrm{am}$ 


\section{Ruth Page}

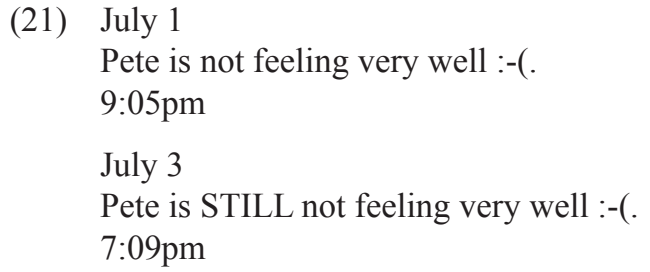

Crucially, the narrative interpretation of these updates is enabled because status updates do not exist in isolation, but are part of an ongoing archive which unfolds over time. Updates which announce a writer's personal attribute may be interpreted as relevant to later events and hence the interpretation of narrative sequence. In the following example, the writer's self-depiction as a "cake-lover" does not constitute a narrative in itself, but within the archive becomes important as the "plot" of her resistance to eating cake emerges.

(22) May 20

Cheryl is a cake lover!

$7: 29 \mathrm{pm}$

May 21

Cheryl is giving up the cake ... as of tomorrow!!

$7: 21 \mathrm{pm}$

May 22

Cheryl did not eat any cake today ... result!!

6:10pm

The narrativity of the Breaking News stories thus varies both in kind (whether the stories depict events or states) and in degree, where events are deemed to be more story-like than states. However, even where updates concern states rather than events, the rhetorical context of the update archive enables the Breaking News to be incorporated into a wider narrative of documented life experiences.

\section{The narrativity of the status stories archive}

Facebook's online environment constitutes a multifaceted database, of which status updates are just one of many components. Unlike other databases, which exhibit little internal development and are even interpreted as anti-narrative structures (Manovich 2001), the catalogue of status updates in Facebook exhibits certain narrative-like properties. As the status updates cited in earlier sections illustrate, the consistent reference to a named individual's experience functions as a unifying interpretive frame across individual episodes, episodes 
which are narrated over the course of time as marked by Facebook's timestamp and thereby imbued with chronological order. However, the narrative properties associated with the archive of status stories depart from the conventions of canonical narrative and are shaped significantly by the distinctive characteristics of the discursive context created by Facebook.

\subsection{Sequence in the status story archive}

5.1.1. Locating the start of the sequence. The narrativity of an event sequence is usually predicated on the inferred relationship between adjacent events (for example, reported in the consecutive clauses of personal narrative, episodes in print literature) and on the event's position relative to a perceived beginning and end of the sequence as a whole. Often the beginning and end of the story are understood in relation to the discourse's point of inception and closure; moments which may function as coordinates of interpretive reference in narrative literature (Rabinowitz 2002). However, the organizational infrastructure of Facebook complicates locating fixed boundaries for the sequence of material formed by status updates archives.

Recency dominates not only the story genres and tellability of the status updates, but also influences the structure in which they appear in the archive. Like e-mail inboxes and blogs, status updates appear in their archive in reverse chronological order, so that the most recently added post appears at the top of the list the reader encounters when opening their profile. If the reader wants to reconstruct the updates in the chronological sequence in which they were posted (and inferred to have occurred), they have to visit the writer's profile page, extract the status stories from the archive of wall interaction, and read backwards from the furthest point in the list. The sequence of status updates has at least two points of inception: the assumed chronological beginning of the reported events (at the end of the writer's archive), or the position of the most recent update (at the start of the reader's news feed). The second of these will continue to change over time as further updates are added to the archive and the less recent updates move further down the list.

\subsubsection{Sequences within a social space. Unlike blogs and e-mail inboxes} which build a single archive of an individual's interactions, when status updates are posted, they appear both in the writer's profile and distributed via news feeds into each of their Friends' profiles. Individual status updates are thus simultaneously positioned in multiple sequences within the social space of the Friend network. The relationship between the sequences can be explained in part drawing on Bakhtin's (1981) concept of the 


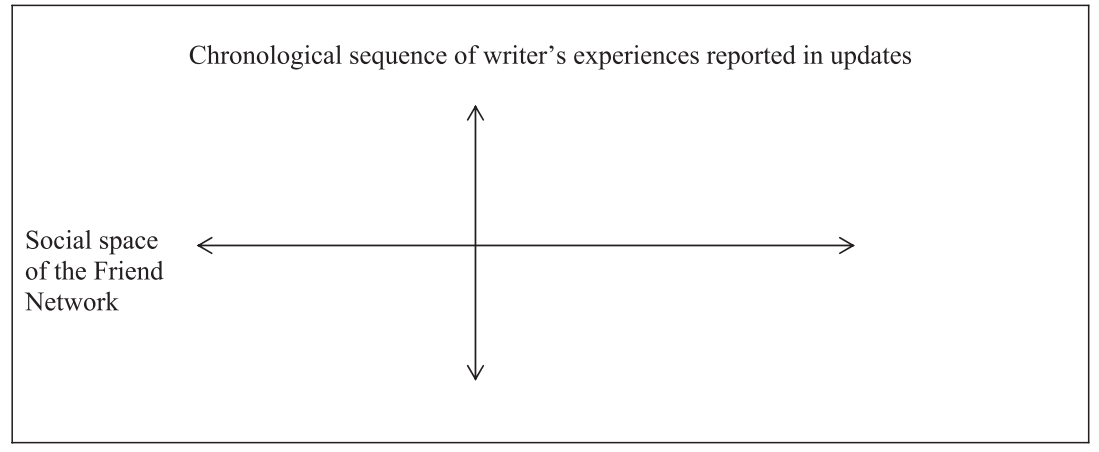

Figure 1. The status updates as a chronotope

Chronotope. The Chronotope plots two intersecting parameters: the time and space of a narrative, here re-appropriated to plot the temporally unfolding sequence of status updates that appears in the writer's profile against the spatial distribution of the updates as they appear in the news feeds of each person in the writer's Friend list. Figure 1 represents the two parameters diagrammatically with the time sequence of the writer's status story archive (the vertical axis) juxtaposed against the social space of their Friend list (represented as the horizontal axis).

Heuristically, we might think of the vertical axis as the "narrative of the individual" - the series of the writer's life experiences documented in status updates. This intersects with the horizontal parameter that emerges as a "narrative of the social network"- the sequence of all Friends' Facebook activity constructed by the RSS technology into a temporal series. The status update "knots together" the life documentation of the individual with their position in the social network, forming a point of intersection between the writer's profile and its distribution across the online context of the Friend community. However, the position of the individual update will continuously change relative to the subsequent Facebook activity generated by an individual (it will move further down the archive as new activity supersedes it as the most recent), and also according to the news feed that it is distributed into across the network. As each news feed is generated uniquely by the ongoing activity of the Friend list of each Friend's contacts, the individual update will be distributed into potentially hundreds of differently combined sequences. It then becomes very difficult to think of the archive as a sequence of status updates constructed as a single chronological thread, with a clear starting point and unified trajectory. Instead, the position of any given status update will occur in constantly changing combinations within the multidimensional networked space of the online community. 
The variable distribution of the status updates, both in the writer's profile and across the network, means that individual updates are not interpreted in relation to a fixed (and meaningful) beginning or endpoint of the text. Instead, the emphasis is thrown upon interpreting the updates as self-contained units. However, while updates can be read without reference to preceding material in the sequence, readers are remarkably adept at creating narratives from nonadjacent story-like material. Prompted by textual and contextual cues that activate narrative scripts stored in the reader's consciousness (Herman 1997), the reader may go on to infer narrative-like connections not explicitly articulated in the updates themselves. In particular, the reader's ability to narrativize the updates combines the assumption of a temporally continuous self as the most basic form of coherence (Linde 1993: 107) along with the human dynamic of anticipation where "each recounted event potentially projects one or more possible next event(s)" (Ochs and Capps 2001: 156). Thus when one status update is posted, this prompts the expectation that another event in the life of writer will follow, whether or not that event is reported in a subsequent update. The timestamp and the participant's name given in every update provide the minimal textual cues at work here, combined with the reader's world-knowledge of the writer's life (for most Facebook Friends are known to each other in the offline world as well as through the online connections).

In some cases, the writer posts a series of updates that follow a thematically connected topic. These sequences contain reference to an event or action that is carried over across more than one update, usually signaled by lexical repetition. For example, consecutive updates can chart the writer's ongoing progress through an extended process, such as completing a domestic chore (as does Fiona):

\section{(23) June 27}

Fiona finished her painting - more tomorrow!

7:49pm Comment

June 29

Fiona the hall is getting it tomorrow!!

$10: 14 \mathrm{pm}$

June 30

Fiona the hall is getting it today!

11:55am

Fiona is exhausted. painted all day and cleaned all night. still loads to do!

$11: 49 \mathrm{pm}$ 
July 2

Fiona is done cleaning.

11:44am

Fiona is done cleaning. the pain this morning gettting up was bad! $12: 08 \mathrm{pm}$

The episodic unfolding of updates in real time can also document the writer's ongoing anticipation of a particular event such as a holiday or birthday:

(24) April 21

Graham is 21 in 3 days!!!

$2: 55 \mathrm{pm}$

April 22

Graham is 21 in 2 days!!!

9:59am

April 24

Graham says THANK YOU TO EVERYONE for their birthday wishes! $\mathrm{X}$.

$11: 40 \mathrm{pm}$

However, it is relatively rare to find sequences of status updates that are thematically connected to a particular topic in this way. It is much more frequent for the status updates to report apparently disparate episodes in the writer's life experiences, as seen in the following update sequences from Jayne and Owen.

(25) May 10

Jayne is not impressed with the random cat that strolled into my living room as bold as brass. Little bastard.

10:54am

May 13

Jayne Is it the weekend yet????

$6: 27 \mathrm{pm}$

May 14

Jayne was gonna go to the gym but is drinking wine instead. Why does this keep on happening to me??

$7: 23 \mathrm{pm}$

(26) June 23

Owen is thinking oh well its Monday then!

12:29pm 
June 25

Owen guess what the train that should stop at Birmingham international isn't! but i'm on it so what shall i do!!!!!

\section{5:56pm}

June 27

Owen is thinking the service on my car will be how much!!!!! 9:23am

Sequences like these where there is little thematic connection between updates are much weaker in narrativity than those centered on particular topics. Although the writers might make references to time, for example "the weekend" or "Monday", these are too generalized to anchor the update at specific points on the calendar from which a defined temporal sequence can be reconstructed. While the ongoing reference to a central participant acts as an interpretive frame, there is no textual content in the updates themselves that would enable the reader to infer logical connections between the reported events to form a cohesive whole. In Herman's (2002: 82) terms, these sequences are "mere successions of doings," rather than exhibiting the tightly knit, interdependent connections required of narrative sequences in its strictest sense.

Instead, the cues which enable the reader to interpret these disparate sequences as stories are found in their discourse context. Although the examples of update sequences are represented here synchronically, that is not how the updates are experienced within the context of Facebook. Instead, the readers receive the updates diachronically, successively ordered according to the time at which the update is written. Because the update is assumed to reflect the writer's thoughts, feelings, or actions at the moment they are being posted, then the events are deemed to be similarly ordered in chronology of the writer's life experience. As noted earlier, the chronology of the discourse creation is marked on the update by Facebook's timestamp, which records to the minute the date and time of each occasion of Facebook activity. In this sense, it is the machine that generates the chronological structure of the status archive, and makes the update archive unlike sharply non-narrative genres like databases or discourse colonies (Hoey 2001).

The sequential character of the status update archive meets the minimal requirements for narrativehood in that it contains updates that are marked by temporal order and consistent reference to the same experiencing agent (the writer). However, the narrativity of the archived updates contrasts with the logical interdependence between units and single overarching structure associated with canonical narratives. In the status archive, these are replaced by episodic narrativity, loosely connected by chronology generated by the act of discourse creation rather than the material reported in the updates themselves. This episodic narrativity is typical of storytelling in online contexts where 
recency is prized over retrospection and the smaller installments of narrative material are readily suited to distribution within a networked space and to the limitations of being presented on a screen rather than a printed page. Given the trend toward using mobile devices (cell phones, e-book readers such as the Kindle) for connecting to Internet services, the importance of small narrative units in online text capable of episodic distribution looks set to continue.

Rather than arguing that this episodic narrativity is non-prototypical, its presence in an increasing range of everyday stories told using forms of computer-mediated communication suggests that our understanding of what characterizes a prototypical narrative (and hence narrativity) is limited and may be even less representative of contemporary narrative practice than has been previously thought. We need, then, to enrich our understanding of narrative forms and functions that have not yet been given as much attention as those that have dominated in fields of sociolinguistic and discourse-oriented narrative analysis.

While the status archive may not resemble canonical narrative, it does share certain characteristics with other story forms, especially the chronicle. The chronicle is usually distinguished from other narrative subgenres (even in some cases excluded from the category of narrative altogether) because while the chronicle contains reported events connected by chronological sequence, they are not organized around a unifying theme or single evaluative focus (Linde 1993: 85). In the same way, the status archive is structured purely by chronological order of posting, rather than by a unified development around a single plot. Individual status updates might contain embedded narratives but these are not arranged around a global structure with a pre-determined teleological end point. Instead, the archive is like a personalized chronicle, where the events are unified by their concentrated focus on the life experiences of the individual writer. The self-portrait that emerges from the archive is analogous to one continuously being created using a pointillist technique. In order to perceive the sequence of status updates as a coherent whole, one must adjust perspective away from seeking linear connections between individual entries in isolation and "fill in the gaps" between status updates, online and offline experience to assume an evolving version of the writer's account of their life.

\section{Conclusion}

A contextualized approach that understands storytelling as situated practice is vital in order to assess the narrative potential of status updates. Viewed as text alone, the present tense, autobiographical episodes distributed across social 
network sites in status updates contrast with the fully fledged, past-tense accounts of personal experience typically scrutinized in sociolinguistics, and are even further removed from the lengthy complexity of literary narratives. However, the difference between status update stories and canonical narratives suggests as much about the narrowness of the corpus from which notions of prototypical narrativity have been derived as it does about the narrative potential of the status update. The parameters often proposed for identifying degrees of narrativity perhaps should not be understood as abstract, decontextualized qualities but rather implicitly shaped by specific nature (medium, context, and genre) of the canonical narratives from which they were originally derived. Without question, these parameters are an important resource that provides points of comparison against which diachronic and generic variation can be plotted, but we must be careful not to endow them with a normative status that marginalizes other, perhaps more prolific examples of storytelling.

The relationship(s) between source data, context, and narrativity is clearly important in assessing the narrative potential of status updates and their archive. The affordances of digital media, especially as filtered through the specific environment of Facebook, influence the distinctive temporal and sequential nature of status update stories. The importance of recency in online technology (Walker Rettberg 2008: 65) lies behind the predominance of Breaking News stories and the emphasis on present time events rather than distant retrospection in the updates. Recency similarly drives the reverse chronological order sequencing of updates within profile archives. The networking capacity of digital technology enables the multi-dimensional distribution of status updates into numerous, constantly changing sequences of Facebook activity, generating a networked web of story episodes rather than a single series of events with a defined point of inception and closure.

The network of Facebook is not simply a digital infrastructure, but is profoundly social. The distribution of stories may be carried by the technology of news feeds, but the stories are written and read by people who know each other. The priority of the ongoing, present-tense stories within the network thus enables a sense of shared experience highly appropriate in an environment that helps you "connect and share with the people in your life" (Facebook homepage), for one effect of an ongoing narrative present is one of intimacy, "through mutual embracing of the temporal context (Dasein) we come to understand one another and our own being as well" (Bennett 2000: 13). The world knowledge brought by the writer and reader to their processing of status updates is also critical in determining the narrative status of these episodes of life experience. It is the experience of producing and receiving status updates diachronically, coupled with the assumptions of ongoing human experience that enables readers and writers to infer a coherent life story behind the personal chronicle that emerges in the archive of updates. 


\section{Ruth Page}

Rather than dismiss status updates as ephemeral, fragmentary forms that fail to match the criteria associated with prototypical narrativity, these small stories have provided fertile territory which enable us to examine the ways in which temporality and sequence are reworked by the online context created in Facebook. As new forms of online collaboration and communities emerge, no doubt our understanding of what might count as story-like will continue to be enriched and extended, providing ongoing debate for the field of narrative theory for years to come.

\section{Notes}

1. Subsequent to the collection of status updates considered in this research, Facebook modified the status update template so that it invited users to "share [ ...] what's on your mind" in order to distinguish the site from its rival, Twitter. How far the change in question influences subsequent updating is beyond the scope of the present essay, but would prove of merit to investigate.

2. The data was collected in May-July 2008, immediately prior to Facebook changing to a new interface. In "old" Facebook, different types of activity were archived separately (e.g., as "wall stories," "status stories," "relationship stories") whereas the new Facebook interface collates all activity together on a single wall. Status updates in new Facebook were given a comment box, enabling Friends to post responses in relation to a particular update.

3. The new Facebook interface would enable further study of the relationship between patterns of commenting, social network, and narrative style, but lie beyond the scope of the present data set.

4. The participants who took part in this study all agreed that the information from their profiles could be used as part of this project following the BAAL guidelines for good practice. In the following paper, where examples of updates are given for illustrative purposes, all names and places have been changed in order to protect the identity of the individual. However, spellings and punctuation used in the original updates have been retained. Facebook's infrastructure does not categorize members according to ethnicity. However, it is clear that ethnicity may well bear on discourse style (indicated through code switching, terms of address, orthographic conventions). In order to limit additional variation, the sample was constrained to one ethnicity: White British.

\section{References}

Bakhtin, Mikhail. 1981. The dialogic imagination: Four essays. Michael Holquist (ed.), Caryl Emerson \& Michael Holquist (trans.), Austin, TX \& London: University of Texas Press.

Bennett, Joel B. 2000. Time and intimacy: A new science of personal relationships. Mahwah, NJ \& London: Lawrence Erlbaum.

Boyd, Danah M. 2008. Taken out of context: American teen sociality in networked publics. Berkeley: University of California doctoral thesis. 
Boyd, Danah \& Nicole Ellison. 2007. Social network sites: Definition, history, and scholarship. Journal of Computer Mediated Communication 13(1). http://jcmc.indiana.edu/vol13/ issue1/boyd.ellison.html (accessed 26 April 2010).

Georgakopoulou, Alexandra. 2007. Small stories, interaction and identity. Amsterdam \& Philadelphia: John Benjamins.

Giora, Rachel \& Yeshayahu Shen. 1994. Degrees of narrativity and strategies of semantic reduction. Poetics Today 22. 447-458.

Herman, David. 1997. Scripts, sequences and stories: Elements of a postclassical narratology. PMLA 112(5). 1046-1059.

Herman, David. 2002. Story logic: Problems and possibilities of narrative. Lincoln, NB \& London: University of Nebraska Press.

Herman, David. 2007. The Cambridge companion to narrative. Cambridge: Cambridge University Press.

Hoey, Michael. 2001. Textual interaction: An introduction to written discourse analysis. London: Routledge.

Hopper, Paul \& Sandra Thompson. 1980. Transitivity in grammar and discourse. Language 56(2). 251-299.

Jakobson, Roman. 1988 [1960]. Linguistics and poetics. In David Lodge (ed.), Modern criticism and theory, 32-56. London \& New York: Longman.

Jenkins, Henry. 2006. Convergence culture: Where old and new media collide. New York \& London: New York University Press.

Kazeniac, Andy. 2009. Social networks: Facebook takes over top spot-Twitter climbs. Compete February. http://blog.compete.com/2009/02/09/facebook-myspace-twitter-socialnetwork/ (accessed 22 April 2009).

Labov, William. 1972. Language in the inner city. Philadelphia: University of Pennsylvania Press.

Leeds-Hurwitz, Wendy. 2005. Making marriage visible: Wedding anniversaries as the public component of private relationships. Text 25(5). 595-631.

Linde, Charlotte. 1993. Life stories: The creation of coherence. New York \& Oxford: Oxford University Press.

Manovich, Lev. 2001. The language of new media. Cambridge, MA: MIT Press.

Norrick, Neal. 2000. Conversational narrative. Amsterdam \& Philadelphia: John Benjamins.

Ochs, Elinor \& Lisa Capps. 2001. Living narrative: Creating lives in everyday storytelling. Cambridge, MA: Harvard University Press.

Rabinowitz, Peter. 2002. Reading narrative beginnings and endings. In Brian Richardson (ed.), Narrative dynamics: Essays on time, plot, closure and frames, 300-313. Columbus: Ohio State University Press.

Ricoeur, Paul. 1984. Time and narrative, vol. 1. Kathleen McLaughlin \& David Pellauer (trans.). Chicago: University of Chicago Press.

Ryan, Marie-Laure. 2004. Narrative across media: The languages of storytelling. Lincoln: University of Nebraska Press.

Ryan, Marie-Laure. 2006. Avatars of story. Minneapolis: University of Minnesota Press.

Ryan, Marie-Laure. 2007. Toward a definition of narrative. In David Herman (ed.), The Cambridge companion to narrative, 22-35. Cambridge: Cambridge University Press.

Schiffrin, Deborah. 1981. Tense variation in narrative. Language 5(1). 45-62.

Sigman, Stuart J. 1991. Handling the discontinuous aspects of continuous social relationships: Toward research on the persistence of social forms. Communication Theory 1(2). $106-127$.

Walker Rettberg, Jill. 2008. Blogging. Cambridge: Polity. 


\section{Ruth Page}

1 Wolfson, Nessa. 1978. A feature of performed narrative: The conversational historical present. Language in Society 7. 215-237.

Ruth Page is Lecturer in English Language in the School of English at the University of Leicester. Her research interests explore the multifaceted connections between narrative theory and language and gender studies, with a special interest in how story forms are being reworked in online contexts. She has published work on these topics within the fields of narrative theory, sociolinguistics, discourse analysis, and stylistics. Address for correspondence: School of English, Attenborough Tower, University of Leicester, Leicester, LE1 7RH, UK<rep22@le.ac.uk>. 